\section{From Spain}

\section{E Lience}

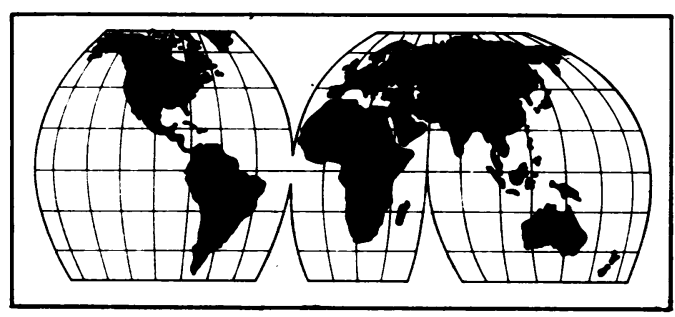

Spain has a population of 38.5 million; its territory extends to part of the Iberian Peninsula, the Balearic Islands and the Canary Islands, and the cities of Ceuta and Melilla on the northern coast of Africa. Spain's territory comprises 17 autonomic communities. The most important cities are Madrid (3.3 million inhabitants), Barcelona ( 1.7 million), Valencia $(766000)$, and Seville $(674000)$.

The number of rheumatologists at public hospitals is 280 ; ideally 530 are needed, which would allow one rheumatologist for 75000 inhabitants. This number will be achieved by the year 2000 provided that the current pace of training of 30 new rheumatologists a year is continued. By the year 2000, however, possibly one rheumatologist for 65000 or 70000 inhabitants will be needed because of the increasing number of elderly in the population. The Sociedad Española de Reumatología and the Sociedad Catalana de Reumatología (one of the seven autonomic societies of rheumatology) have just completed parallel studies on the needs of the rheumatology services.

As in other countries there is a shortage of rheumatologists, and, in addition, they are inappropriately distributed throughout the country, being concentrated in the most important cities. Fortunately, these deficiencies are lessening as autonomic governments are creating rheumatology posts at hospitals in the smaller cities and, therefore, a rational distribution is being progressively achieved. Additionally, since 1986, training of hospital doctors as rheumatologists, to act part time in primary health care, has been carried out, and thus coverage at the larger hospitals has been extended.

Most young rheumatologists have been trained at Spanish hospitals. Numerous Spanish rheumatologists have been trained at or have stayed in the United Kingdom so the influence of British rheumatology is strong. Because of the proximity and the prestige of some French centres, some students go to Paris, Toulouse, Montpellier, or other cities; other rheumatologists travel to Mexico, which has an accredited school. Few Spanish rheumatologists have been trained in the United States of America.

Spanish rheumatologists are under a great deal of pressure at work as there are an insufficient number to meet the existing demand. Few public hospitals with newly formed rheumatology units have sufficient staff. These difficulties have highlighted the need for research. Government funding for research has been increased during the past two years but some time must elapse before results will be seen.
The Sociedad Española de Reumatología (Villanueva, 11, 28001 Madrid) has 850 members; the chairman (currently Dr P Barceló) and secretary (Dr C Alegre) are nominated for two years. The main objectives of the society are: (1) To study the existing rheumatology services in Spain and to influence the administration to improve these services. (2) To work with the schools of medicine to produce a good study programme for undergraduates. (3) To adapt training of rheumatologists to the requirements of the European Community. To achieve this aim study has been increased to five years - two in internal medicine, three in rheumatology. (4) To maintain inter national relations. Units of rheumatology are encouraged to take part in annual meetings of the British Society for Rheumatology because of the important formative and stimulating role that such meetings have in the education of young rheumatologists. In 198823 Spanish communications and posters were selected-about $10 \%$ of the total. (5) To improve and stimulate clinical and basic research projects that are already under way. (6) To carry out epidemiological studies; an epidemiological study of hyperuricaemia has already been developed.

In 1988 the director of the service of rheumatology of the Hospital Clínic i Provincial in Barcelona, Dr J Rotés-Querol, retired. He is known for his description of senile vertebral ankylosing hyperostosis and for his studies on ankylosing spondylitis, brucellar osteoarthritis, and psychogenic syndrome of locomotive apparatus. Dr Rotés-Querol showed perspicacity in his semiological analysis of patients and in clinical research; he guided numerous rheumatologists of the present generation.

The Sociedad Española de Reumatología meets every two years; the last meeting took place on 9-12 May 1990 in Palma de Mallorca. In the intervening years members meet informally, usually in Madrid. The last such meeting took place on 22-23 June 1989; 26 communications and 36 posters were presented. Drs Graciela S Alarcon (systemic progressive sclerosis), Martha Skinner and M B Pepys (amyloidosis) were the guest speakers.

The XVIIIth ILAR congress of rheumatology (chairman: Dr E Asensi; executive president: Dr P Barceló) will take place on 4-10 July 1993 in Barcelona.

The journal Revista Española de Reumatología was founded in 1974; it appears every two months. Five thousand copies are printed; 500 of these contain an English translation of original research and are sent to foreign rheumatology departments. The journal has a committee of experts and is included in Excerpta Medica and Biosis. Its address is: Travessera de Gràcia, 17-21, 080021 Barcelona.

The Liga Reumatológica Española (chairman: Dr J M Ferrer) is a society of social action dealing with problems of patients with rheumatic diseases. The society publishes pamphlets to assist patients and give grants and diverse prizes. Its address is:

Cid, 4, 28001 Madrid.
Passeig Vall d'Hebron, s/n, 08035 Barcelona, Spain E Lience 